\title{
Research on the Composition Art of Tang Dynasty Tomb Mural Paintings in Shaanxi with Xi'an Area as the Center
}

\author{
Lei Wang \\ School of Design Art \\ Xijing University \\ Shaanxi, China
}

\author{
Yuan Shao \\ Academy of Fine Arts \\ Shaanxi Normal University \\ Shaanxi, China
}

\begin{abstract}
Mural painting is a kind of art on the wall. As an important type of traditional Chinese mural paintings, tomb mural painting has become a precious cultural heritage of the world through the historical and cultural development for thousands of years. The Tang Dynasty is the golden age for the development of tomb mural paintings. At present, about two thirds of the nearly two hundred mural paintings are discovered in Guanzhong region with the Xi'an as the center in this period. It prominently shows majestic momentum and exquisite skills of paintings in the Tang dynasty and represents the bustling social life of the Tang dynasty again, which has crucial artistic value and academic value. Mural composition plays an important role in expressing contents and themes of murals. This paper, based on the composition, the important factor of mural artistic features, analyzes the composition of tomb mural paintings in the different periods of Tang dynasty in Xi'an area, so as to explore the development of tomb mural paintings in the Tang dynasty. The research on composition provides important basis for period division of mural, and offers better creative inspiration and source for modern painting creation.
\end{abstract}

Keywords-Xi'an area; mural painting in Tang dynasty; composition art

\section{INTRODUCTION}

Mural painting is drawn on rocks or walls and is one of the earliest painting forms in human history. People in primitive society depicted various pictures on rocks and caved walls through minerals and animal tallow to record life, which is the earliest mural form. Generally speaking, murals can be divided into cave murals, tomb murals and temple murals.

\section{GENERAL OF TANG DYNASTY TOMB MURAL PAINTINGS IN XI’AN AREA}

The generation and development of tomb mural paintings is the result of art evolution and changes of social history and ideological culture. As an important branch of Chinese mural, tomb mural paintings often appear on the top, wall and both sides of corridor. The tomb mural paintings of Tang dynasty is a treasure and occupies a vital position in Chinese art history. The excavation of it begins at the early 20th century. Archaeologists and explorers from other countries discover relics of some paintings and murals in tombs of Tang dynasty in Xinjiang and obtain valuable data. At present, the number of mural tombs in Tang dynasty that have been unearthed or cleaned exceeds one hundred and fifty. More than $80 \%$ are located in Guanzhong region centering on Xi'an. According to time clue, twenty-three mural tombs were unearthed in 1950s, four in 1960s, twenty-seven in 1970s, twenty-eight in 1980s and nineteen in 1990 s, more than five at the early 21 st century.

Nowadays, tomb mural paintings of Tang dynasty have become precious cultural heritage of the world. Most tomb masters in Tang dynasty at Xi'an area have high status, including imperial household, relatives of the emperor, princes and dukes, minister and high officials. The tomb mural paintings of Tang dynasty belongs to aristocratic culture and vividly records cultural landscapes like ancient laws and regulations, social custom, religious belief and ideas at that time. ${ }^{2}$ There are a number of tomb mural paintings of Tang dynasty in Xi'an area, including more than two thousand objects in Shaanxi History Museum. The representative royal tombs include Li Shou's Tomb, Prince Yide's Tomb, Prince Zhanghuai's Tomb, and Princess Yongtai's Tomb.

\section{THE PERIOD DIVISION OF STYLES OF TANG DYNASTY TOMB MURAL PAINTINGS IN XI'AN AREA}

Tang dynasty is the peak period of Chinese painting development. According to the records of theory of painting in Tang, Song, Ming and Qing dynasties, there are about four hundred painters in Tang dynasty, and more than one hundred people participate in the mural creation. They create massive works in palace, temple and tomb. The large quantity and exquisite quality represents the peak stage of Chinese mural. On artistic features of mural, it forms perfect structural system on aesthetics, material, composition, modeling and color application.

\footnotetext{
${ }^{1}$ Zheng Yimo. Summary on Research of Murals in Tombs of Tang Dynasty [J], Theory Front, page 27, Mar.2009

${ }_{2}^{2}$ Li Xingming. Research on Tomb mural paintings of Tang Dynasty [M], Xi'an: Shaanxi People's Fine Arts Publishing House, page 1, 2005
} 


\section{A. The Artistic Features of Tang Dynasty Tomb Mural Paintings in Xi'an Area}

In general, the artistic style can be divided into three development periods: In early period, it inherits the painting style of the Northern and Southern Dynasties, combining the thin and the dense and transforming from sparse, magnificent and powerful and a little dull style to fluent, extended and bright style. The murals mainly depict life, guard honor and hunting of tomb masters. The dense style is shown in Princess Changle's Tomb and Prince Yide's Tomb and the thin style in Zhishi Fengjie's Tomb and Prince Zhanghuai's Tomb. In middle period, it integrates several styles, concise, bold and unconstrained, having the lasting appeal of "Wu Daozi's Painting Style". Most are Yingzuo wood structure in tombs, becoming residence of the dead in the nether world. In later period, it improves the styles in middle period as well as innovates, taking the lead of exquisite painting style of figures and bird-and-flower painting with exact delineation and enriched colors in the Five Dynasties. ${ }^{3}$

On theme, most tomb mural paintings reflect previous life of the dead, and some decorative patterns like deities, myths and legends, the sun, the moon and the stars. It prays for the dead and plays the role of reflecting social ideas and educating. On the whole, the themes of murals in tombs of Tang dynasty present obvious periodicity. In early Tang dynasty, it lasts the style of tomb mural paintings of Sixteen States and the Northern Dynasties; in reign of Tang Gaozong and Wu Zetian, it applies the Yingzuo wooden buildings and the "residence" characteristics are further strengthened; in reign of Tang Zhongzong to Tang Xuanzong and Kaiyuan Period, Yingzuo pillars are painted on portal and corridor to create courtyard atmosphere and it increases recreation scenes; in reign of Tang Xuanzong to the end of Tang dynasty, tomb chambers are painted with four ancient Chinese mascots, dance accompanied by music and screen. The Yingzuo buildings disappear and scenes of honor guard and travel are not painted on tomb passage. ${ }^{4}$

Because the tomb mural painting of Tang dynasty is located in Central Plains, the line drawing is influenced by social popular painting style. Lines play an important role of establishing framework and signifying. The murals often start with very little added color and use ink to draw lines. Double lines are seen in most works. The lines of figure modeling are round, correct, strong and rise and fall with reasonable layout, embodying the inherent relationship from "Zhangjiayang" in early period of Tang dynasty to "Wujiayang" in middle period of Tang dynasty and "Zhoujiayang" in later period of Tang dynasty. The expressions of figures are vivid. Lines of a few feet are used to depict clothing texture. It is done by a wielding of the brush to make the picture as vivid as life.

The coloring of Chinese painting mainly follows the principle of "conformity to kind in applying colors", which

\footnotetext{
${ }^{3}$ Bai Wei. Exploration on Artistic Style of Mural Painting in Tomb Chamber of Tang Dynasty [J], Journal of Shaanxi Normal University (Philosophy and Social Sciences Edition), volume 30, issue 2, page 89, Jun.2001

${ }^{4}$ Qi Dongfang, Zhang Jing. Comparative Study on Murals in Tomb of Tang Dynasty and Murals in Takamatsuzuka Tumulus [J], Journal of Tang Studies, Volume i, 1995, page 447-472
}

shows the subjectivity, chanciness and expressivity of traditional Chinese painting. The colors of tomb mural paintings of Tang dynasty include mineral colors and metal colors, including bright red, Vandyke red, ocher and stone yellowing to form the simple, graceful and exuberant romantic charm. Gold foil and silver foil are properly used in painting. The coloring methods consist of flat coating, rendering, color change and rolling dyeing. Flat coating and rendering are mainly applied to cloth and waistband. Rolling dyeing is applied to face of people, such as the application of concaveconvex dyeing.

\section{B. The Period Division of Styles of Tang Dynasty Tomb Mural Paintings In Xi'an Area}

The tomb mural painting of Tang dynasty lasts for a long time. Scholars research through dividing it into periods. Su Bai divides the 24 mural paintings excavated in Xi'an area into five periods: the first period is from the reign of Tang Gaozong to the middle period of Tang Taizong; the second period is the reign of Tang Gaozong; the third period is from 706 to 729 ; the fourth period is from 745 to 787 ; the fifth period is from the reign of Tang Xianzong to the end of Tang dynasty. Li Xingming divides tomb mural paintings of Tang dynasty into four periods: the first period is from the reign of Gaozu to Gaozong (618-683); the second period is from the reign of $\mathrm{Wu}$ Zetian to Ruizong (684-712); the third period is from the reign of Xuanzong to Jingzong (713-826); the fourth period is from the reign of Wenzong to Aidi (827-907).

\section{THE COMPOSITION ART OF TOMB MURAL PAINTINGS OF TANG DYNASTY IN XI'AN AREA}

Composition comes from Latin. The original meaning is constitution or layout. "Composition refers to orderly combine visual forms like shape, color, material and texture to form an organic whole picture that can convey contents, emotions and ideas." ${ }^{5}$ Composition of mural is a key factor of its artistic features. It is called "operation location", "layout", and "orderly way" in traditional Chinese painting theory. Painters make proper arrangement for paintings according to law of things and art rules. It occupies the position of "the priority among priorities in painting" in Chinese history. Painters dispose the painting through layout, echo, spacing, exposure, balance, change and blank. The form of architectural space also influences mural composition. For example, the composition of tomb mural paintings is distinctly different from that of cave mural. When the wall is irregular shape, curved shape or triangle, and semicircle, the composition of murals must change accordingly.

The tomb mural paintings of Tang dynasty in Xi'an area have large quantity and high artistic level. Its composition is different from that of other types of mural. The size of mural is confined to inner space of tomb chamber. So to speak, tomb mural paintings have adaptive composition. Closely linked to building structure of tomb chamber, it has unique aesthetic characteristics of art. It shows different features in mural paintings at different periods of Tang dynasty. Next, the author

${ }^{5}$ Zhang Lihua. Creation and Composition [M], Beijing: People's Fine Arts Publishing House, page 16, 2002 
describes the composition features at different periods by taking some representative tomb mural paintings of Tang dynasty as examples.

\section{A. The Composition in Early Period}

The representative tomb mural paintings of early Tang dynasty is Li Shou's Tomb in the fourth year of Zhenguan (630 A.D.) located in Jiaocun Village of Sanyuan County. It faces south and consists of tomb passage, portal, dooryard, small niche, and corridor and tomb chamber. Murals can be found on these places other than small niche and dooryard. The tomb passage has seventeen meters long and the middle part is divided into upper and lower layers. The lower layer has Horse Riding Travel Painting of east-west symmetry and the upper layer has Flying Apsaras and Hunting Painting. The mural on portal is conserved well. East and west walls of portal and dooryard are painted with twelve honor guards on foot and each consists of eight to ten people; halberd display painting with seven halberds on each frame. Room corridor locates behind the halberd frame and three arrays of honor guard are beside the halberd frame. Architectural complex is painted on the south wall of the portal and corridor. East and west walls of the corridor gate are painted with flying Apsaras and figures. East and west walls of the middle corridor are painted with eleven chamberlains of different forms. The top of corridor is painted with large honeysuckle pattern and flying Apsaras towards the tomb chamber. The east wall of the back end of corridor is painted with temple with acolytes and the west wall is painted with Taoist temple, directly reflecting the previous life of tomb master. The layout of murals in $\mathrm{Li}$ Shou's Tomb is complicated. The honor guard painting depicted on the tomb passage, portal and dooryard inherits the style of the Northern Dynasties and is inherited by mural tombs in glorious age of Tang dynasty. The subfield design of murals in tomb passage also appears in Lou Rui's Tomb of Northern Qi Dynasty.

The murals in Li Shou's Tomb from the gate of tomb passage to the tomb chamber use narrative composition mode. Different themes are painted on upper and lower walls of the tomb. The representative one is the Honor Guard Painting. Murals with honor guards gather in capital city of central Shaanxi plain, located on east and west walls of the tomb passage and sometimes extending to portal and dooryard. The tombs of members in imperial household at early Tang dynasty pay attention to honor guard, different from tombs of imperial family after this period. The honor guard in Li Shou's Tomb consists of honor guard on horseback and honor guard on foot with more than two hundred people, occupying a large area in the tomb and extending from the tomb passage to east and west walls of the fourth portal. Painters divide the murals into two parts, honor guard on foot and hunting, according to building type. Although it has large quantity of people, they are not crowed, fully showing the density relations of traditional Chinese painting composition. Vehicles, horses and figures are well-proportioned, leaving some blanks. Front and side faces of figures are painted in the same composition, which can emphasize close connection of people. This kind of composition put scattered figures in closed space, combining changes and unification.

\section{B. The Composition in Middle Period}

The representative in middle period of Tang dynasty is the mural in Prince Yide's Tomb. Prince Yide's name is Li Chongrun, the eldest son of Tang Zhongzong. He was buried in Qian Tomb of Tang Empire (706 A.D.). His tomb was called imperial tomb. The tomb consists of tomb passage, portal, dooryard, small niche, and corridor and tomb chamber. Murals are painted on them other than the small niche. The gate of tomb passage is painted with honor guard. The God in the East worshipped by the Taoists and the city wall and watchtowers are behind the honor guard on the mural painting. East and west walls of the portal are painted with manservant, chamberlain and maid. Walls on both sides of dooryard have mural paintings, including four large halberd frames. Tiger head is below the halberd head and red, green and yellow ribbons are under the tiger head. Two arrays of honor guard stand before the halberd frame. It is the first time to discover twelve halberd frames in Shaanxi. West wall is painted with a coach carrying a person in red robe. Four people stand in front of the coach, two holding up circular fan. Two people behind the coach stand face to face. East and west walls of front and back corridors are painted with maids. The top of corridor is painted with lotus flower, creeping weed and crane. Mural paintings can be found on wall of the front tomb chamber. East wall is painted with two mural paintings with 28 maids holding articles. The top is painted with celestial bodies, the sun in the east, the moon in the west, white stars densely covered at both sides of the Milky Way. Mural painting on east wall of the back chamber is complete. There are 19 maids holding articles. The top is painted with celestial bodies, the sun in the east, the toad in the west, as well as the Milky Way and stars.

Although the mural painting in Prince Yide's Tomb is magnificent, the layout is very rigorous. New themes appear in composition. The most mentionable is watchtower and city wall painted on east and west walls of tomb corridor. The height and the width of the painting of two watchtowers are the same, $280 \mathrm{~cm}$. The area of each is about 9 square meters. The wall outside the watchtower extends to the north with rolling mountain range in the distance. East and west walls locate one parent watchtower and two subsidiary watchtowers, forming "three watchtowers". (As shown in Fig. 2) This painting reminds people of drawing lines with the aid of a ruler in drawing palatial buildings in traditional Chinese painting. Similarly, it uses "scattered perspective" to deal with aerial perspective relation of objects. Specifically speaking, it uses parallel perspective without vanishing point. ${ }^{6}$ Observation methods like looking down, looking up and looking at the front horizontally are used. Methods such as shift perspective and multi-point perspective are also applied to the overall architectural composition. The watchtower on mural painting in Prince Yide's Tomb is built on high platform. The overall layout uses "deep far perspective method" in drawing lines with the aid of a ruler in drawing palatial buildings. Perspective methods like deep far, overlooking and scattered point are applied to depict the front, the side and the top of buildings with strong three-dimension effect. It also organizes buildings at different positions in the same picture. The

\footnotetext{
${ }^{6}$ You Xinmin. Boundary Painting Techniques [M], Beijing: People's Fine Arts Publishing House, page 12, 1989
} 
landscape painting in the watchtower painting has the embryonic form of independent mountains-and-waters painting, which is a novel theme. The landscape in painting starts from the top of the parent and the subsidiary watchtowers on south wall and extends to the top of honor guard in the north. The mountains in the southern section are placid with bright composition and three-dimension effect. The landscape painting on the whole painting gets rid of the composition mode with figures superior to landscape in the early period. Although it also serves as the background, it arrays from south to north. The composition and state is abundant in changes. Compared with the big background, several small rocks at the foot of the mountain are collocated properly. The landscape painting in watchtower painting prominently shows the density relation and sense of space between the front and the back sceneries.

\section{The Composition in Later Period}

With the development of politics and economy in late Tang dynasty, the tombs of members of imperial household, aristocrats, ministers and high officials after glorious age of Tang dynasty are further simplified. The structure of tomb chamber, contents and patterns of mural painting also change. Mural paintings on tomb passage disappear gradually and Yingzuo wood structure reduces greatly. Themes like hunting, travel, honor guard and arrays of halberd are not popular. Scenes in daily life such as dance accompanied by music, banquet, figures under tree, flowers and birds, mountains and waters become the themes of tomb mural paintings.

Princess Tangan's Tomb is a representative imperial tomb in late Tang dynasty. It was built at about 784 A.D., consisting of tomb passage, corridor, two small niches and tomb chamber. East and west walls of corridor are painted with six waiting men and maids. These maids are in wide skirt, combing high coiffure and having plump figure, which is the typical modeling of beautiful women in middle Tang dynasty. The roof of tomb chamber is painted with celestial phenomena like clouds and stars. The edge of adjacent walls in tomb chamber is painted with red frame. The west wall has painting of flowers and birds. The east wall is damaged heavily. A beautiful woman and a man as well as rocks, flowers and birds are remained in the painting on the south side. The north wall is painted with God of the Northern Sky, propitious cloud, a waiting man and woman. The painting on south wall has rosefinch with six propitious clouds below which is the round lace pad. The composition is fresh and natural with proper location and distance as well as skillful layout.

After the middle and late Tang dynasty, the prominent feature of composition is changeful themes and increase of screen painting. Screen painting appears in Princess Tangan's Tomb like the unique one with flowers and birds. Bird-andflower painting develops rapidly in the middle and late Tang dynasty. Records about these painters in historical materials also increase obviously. The west wall of Princess Tangan's tomb chamber has a single bird-and-flower painting known as the first one with clear calendar year at present. (As shown in Fig. 3) Each side stands a tree on the painting and the treetops overlap on the top in the center of the painting. The top right corner has two awing pheasants. There is a round basin with four birds on the edge, two pigeons on the left standing face to face and two pheasants on the right. Different flowers intersperse around the scenery. This screen painting has full composition and depicts grass and trees, flowers and birds, showing us vivid and beautiful scenery with bird's twitter and fragrance of flowers. The still round basin and moving birds are full of vitality.

The theme of screen painting in Tang dynasty is extensive, covering figures, landscapes, flowers and birds. The painting of figures, flowers and birds on six screens popular in this period is distinctive. The screen painting has direct influence on the composition of landscape painting. "The screen composition directly influences the composition of wash painting. The most obvious feature is that the landscape changes from lateral composition in the early Tang dynasty to longitudinal composition. The landscape also has corresponding changes. The pursuit for sceneries in high, far and deep areas influences the composition mode of landscape painting until the Five Dynasties and the Northern Song Dynasty." 7

\section{CONCLUSION}

According to the above analysis on the composition of tomb mural paintings in three periods of Tang dynasty, it is obvious that the composition of tomb mural paintings is similar to that of the traditional Chinese painting. Both of them show objects through multi-angle perspective to make the composition feast our eyes. Because of different politics, economy, humanistic conception and structure of tomb chamber in the three periods, the composition also differs. Specifically speaking, the tomb mural paintings of early Tang dynasty focus on inheritance and pay attention to composition of grand scenes like honor guard. The composition is narrative in a long scroll, which is an important feature distinguished from other two periods. The themes center on figures and express their inner relationship. In the middle period, the themes are various, and long narrative scrolls reduce but the complicated and complete composition of single scene increases. The themes about landscape increase obviously. For example, a landscape painting with single composition is unearthed in Han Xiu's tomb. In the late period, the tomb mural paintings prefer single composition of life scenes to the composition of long scroll, which almost disappears at that time. Furthermore, it focuses on screen composition with themes of flowers and birds, and appears bird-and-flower painting of single complete composition. The changes of composition in three periods embody the inheritance and development of composition of tomb mural paintings in Tang dynasty.

As a branch of traditional Chinese painting, the tomb mural painting has unique development features in historical development, forming the development process from Han and Wei dynasties to Sui and Tang dynasties, the Five Dynasties and Ming and Qing dynasties. The flourish of mural painting in imperial tomb of Tang dynasty settles the basic features of

\footnotetext{
${ }^{7}$ Zhao Shengliang. Ink Landscape Painting in Murals of Tang Dynasty, Memoir of International Symposium on Murals in Tombs of Tang Dynasty, Xi'an: Sanqin Publishing House, page 309, 2006.
} 
Chinese tomb mural paintings. The prominent artistic features of mural paintings in Tang dynasty also represent the peak of Chinese painting development. At the meantime, it is also the mature period of composition of mural painting. The analysis on its artistic features especially the composition form helps us to find the source of mural painting in tombs of Tang dynasty and provides some references for the creation of contemporary mural as well as Chinese painting, so as to realize the continuous inheritance, development and innovation of the traditional Chinese classic painting pattern in artistic creation. .

\section{REFERENCES}

[1] Wang Renbo, Analysis on Theme of Mural in Prince Yide's Tomb of Tang Dynasty [J], Archaeology, 1973(6)

[2] Shang Yuanhe, On Murals in Tombs of Princes Zhanghuai and Yide and Murals in Takamatsuzuka Tumulus[J], No. 624 Ancient Art, 1973

[3] Shaanxi History Museum, Committee for Management of Cultural and Historical Relics, Exploration on Murals in Li Shou's Tomb of Tang Dynasty [J], Cultural Relic, 1974(9)

[4] Su Bai. Layout and Content of Tomb mural paintings of Tang Dynasty in Xi'an Area [J], Acta Archaeologica Sinica, 1982(2)

[5] Chen Anli, Ma Yongzhong. Princess Tangan's Tomb in Wangjiafen of Xi'an [J], Cultural Relic, 1991(9)

[6] Qi Dongfang, Zhang Jing. Comparative Study on Murals in Tomb of Tang Dynasty and Murals in Takamatsuzuka Tumulus [J], Journal of Tang Studies, Volume i, 1995

[7] Li Guozhen, Changing Forms of Feather and Flourishing Flowers and Plants-Murals with Painting of Flowers and Birds in Princess Tangan's Tomb [J], Bulletin of Shaanxi History Museum, 1996(3)

[8] Shaanxi Institute of Archaeology, Newly Unearthed Murals in Tomb of Tang Dynasty in Shaanxi [M], Chongqing: Chongqing Publishing House, 1998

[9] Chu Qien. History of Chinese Mural [M], Beijing: Beijing Arts and Crafts Press, 2000

[10] Shaanxi History Museum, Collected Works of Research on Murals in Tomb of Tang Dynasty [M], Xi'an: Sanqin Publishing House, 2001 